\title{
白龙江上游地区森林植物群落物种多样性的研究
}

\author{
郭正刚 ${ }^{12}$ 刘慧霞 ${ }^{2}$ 孙学刚 $\left.\right|^{3}$ 程国栋 ${ }^{1}$ \\ (1 中国科学院寒区旱区环境与工程研究所冻土工程国家重点实验室 兰州 730000) \\ ( 2 兰州大学草地农业科技学院 兰州 730020) \\ (3 甘肃农业大学林学院 兰州 730070)
}

\begin{abstract}
摘 要 白龙江上游地区属长江防护林工程重点地区之一。根据 36 个样地的调查资料, 分析了该地区森林植物 群落物种多样性的特征 :群落内各层物种丰富度指数的大小顺序为 灌木层 $>$ 草本层 $>$ 乔木层” 均匀度指数变化 比较复杂, 在杜鹃巴山冷杉 (Rhododendron fastigiatum-Abies fargesii) 林中为 草本层 > 灌木层 > 乔木层”, 在苔藓巴山 冷杉林中为 乔木层 $>$ 灌木层 $>$ 草本层” 其余群落中为 灌木层 $>$ 草本层 $>$ 乔木层” ;多样性指数的大小顺序为 乔 木层 < 灌木层和草本层”, 而灌木层与草本层的多样性指数随林分郁闭度变化而变化, 在郁闭度 $30 \%$ 的杜鹃巴山冷 杉林中, 草本层大于灌木层, 在有闭度 $47 \%$ 的箭竹巴山冷杉林中, 草本层和灌木层相当, 在有闭度 $55 \%$ 以上的各个 群落内, 灌木层大于草本层。同一海拔不同坡向群落的物种多样性表现为分布于阳坡的油松 (Pinus tabulaeformis)林 大于分布于阴坡的草类云杉 ( Picea asperata) 林。物种多样性沿海拔梯度的变化表现为随海拔升高先降低后增加， 从海拔 $2400 \mathrm{~m}$ 的栎类阔叶林, $2600 \mathrm{~m}$ 的草类云杉林, $2800 \mathrm{~m}$ 的箭竹 (Sinarundinaria nitida)巴山冷杉林, 到 $3000 \mathrm{~m}$ 的苔藓巴山冷杉林和 $3200 \mathrm{~m}$ 的杜鹃巴山冷杉林, 物种多样性依次下降, 到海拔 $3400 \mathrm{~m}$ 的高山杜鹃( Rhododendron fastigiatum) 灌丛, 物种多样性增加。物种多样性在紫果云杉( Picea purpurea)林的演替系列中表现为随群落演替发展 而增加, 后降低, 在针阔混交林阶段达到最大。
\end{abstract}

关键词 森林群落 物种多样性 白龙江上游地区

\section{CHARACRISTICS OF SPECIES DIVERSITY OF PLANT COMMUNITIES IN THE UPPER REACHES OF BAILONG RIVER}

\author{
GUO Zheng-Gang ${ }^{1}{ }^{2}$ LIU Hui-Xia ${ }^{2}$ SUN Xue-Gang ${ }^{3}$ and CHENG Guo-Dong ${ }^{1}$ \\ (1 State Key Laboratory of Frozen Soil Engineering, Cold and Arid Regions Environmental and Engineering Research Institute , \\ the Chinese Academy of Sciences , Lanzhou 730000 , China) \\ (2 School of Pastoral Agricultural Science and Technology , Lanzhou University, Lanzhou 730070 , China) \\ (3 School of Forestry , Gansu Agricultural University , Lanzhou 730070 , China)
}

\begin{abstract}
The upper reaches of Bailong River, a significant branch of the Yangtze River , is one of the important regions in the Yangtze River Natural Forest Protection Project. Based on the survey and the data from 36 plots, characteristics of species diversity of plant communities in the upper reaches of Bailong River were discussed in this paper. The study showed that richness index varied as follows : tree layer $<$ herb layer $<$ shrub layer. The evenness indices varied between communities as follows : a) Rhododendron fastigiatum-Abies fargesii community : herb layer $>$ shrub layer $>$ tree layer ; b) moss- $A$. fargesii community : tree layer $>$ shrub layer $>$ herb layer ; and c) other communities : shrub layer > herb layer $>$ tree layer. Diversity indices in tree layer were lower than that in herb layer and in shrub layer. While the diversity indices between herb layer and shrub layer varied with shade density, i.e. greater the shade density, lower the diversity indices in herb layer. When shade density of stand was about $45 \%$, diversity index in herb layer were almost equal to that in shrub layer; when shade density of stand was about $30 \%$, diversity index in shrub layer were lower than that in herb layer ; when shade density of stand was above $55 \%$, diversity indices in shrub layer were higher than that in herb layer. General richness index , evenness indices and species diversity of Pinus tabulaeformis community distributed on the sunny slope were higher than that of the grass-Picea asperata community growing on the shady slope along the same elevation zone $(2500-2700 \mathrm{~m})$. The study detected that general species diversity and general evenness indices of different plant communities decreased gradually from broadleaf mixed community dominated by Quercus liaotungensis at $2400 \mathrm{~m}$ elevation , to grasses-Picea asperata community at 2600 m elevation, to bamboo (Sinarundinaria nitida)- $A$. fargesii community at $2800 \mathrm{~m}$ elevation, to moss- $A$. fargesii community at $3000 \mathrm{~m}$ elevation, to $R$. fastigiatum- $A$. fargesii community at $3200 \mathrm{~m}$ elevation
\end{abstract}


zone , and then progressively increased in $R$. fastigiatum shrubs from $3400 \mathrm{~m}$, with altitudinal increase. The study also indicated that species diversity and evenness index gradually increased from shrubs stage dominated by Spiraea alpina and Sibiraea angustata to broadleaf mixed forest stage dominated by Betula albo-sinensis , to broadleaf and needleleaf mixed forest stage dominated by B. albo-sinensis and Picea purpurea, and then decreased at the needleleaf community stage dominated by $P$. purpurea in the natural succession series of $P$. purpurea community after artificial logging.

Key words Plant community , Species diversity , Upper reaches of Bailong River

生物多样性是维持生态系统持续生产力的基础 （李永宏，1995）,也是人类赖以生存的条件。生物多 样性的研究已成为当前群落生态学研究中十分重要 的内容和热点之一(黄忠良等,2000)，但受空间尺度 和生态系统复杂性的影响, 目前生物多样性的研究 多限于遗传多样性、区域景观多样性和物种多样性， 而且以物种多样性的研究较多。国内对植物群落物 种多样性的研究主要集中于多样性在环境梯度和群 落演替过程中的变化(马克平等,1995;陈北光等， 1995 ;常学礼等,1997; 朱锦禁等,1995;藏润国等, 1997 ;高贤明等,1997; 李新荣等,2000;沈泽昊等， 2001 ;温远光等, 1998)，放牧对植物多样性的影响 （杨利民等，2001）植物群落多样性对自然因子和人 为因子的响应 (常学礼等,2000;李振基等,2000;刘 宏茂等,1998) ,而这些研究从各自的地理背景和生 产实际出发, 主要反映草原地带和热带亚热带地区 植物群落的多样性特征(白永飞等,2001 潢忠良等， 2000 杨利民等，2001）结论很难在西北地区大范围 推广应用。白龙江上游地区是以涵养水源为主的天 然林区，也是年自产水径流量 62.8 亿 $\mathrm{m}^{3}$ 的白龙江 (长江上游嘉陵江一级支流)的发源地，不仅在甘肃、 而且在西北乃至全国具有重要的战略地位。复杂的 山地生境蕴育了多种多样的森林群落,但在半个多 世纪的开发利用中，森林面积急剧减少 林分生产力 下降, 森林资源濒临枯竭(郭正刚等,1999)。本区植 物区系成分复杂, 替代现象明显, 是东西、南北植物 交流的关节点(孙学刚，1993），林分人工更新不良 （曲永宁等，1996），天然次生植被具有较强的水文效 应(尹作栋等,1991)。研究该地区森林群落植物的 物种多样性的特征, 加深对本区植物群落性质的认 识, 为本区生物多样性保护与持续利用提供理论依 据。

\section{1 研究地区与方法}

\section{1 研究地区自然概况}

研究地区位于青藏高原东北边缘, 甘肃省南部, 地理位置为 $102^{\circ} 46^{\prime} \sim 104^{\circ} 52^{\prime} \mathrm{E} 、 33^{\circ} 04^{\prime} \sim 35^{\circ} 09^{\prime} \mathrm{N}$ 。
受高原和东南季风影响，气候以北温带高寒湿润气 候为主, 年均气温 $4.7 \sim 12.7{ }^{\circ} \mathrm{C}$, 年降水量 448.9 $911.6 \mathrm{~mm}, \geqslant 0{ }^{\circ} \mathrm{C}$ 的年积温 $2000 \sim 3500{ }^{\circ} \mathrm{C}$ 。土壤从 高海拔到低海拔依次为寒漠土、寒冻毡土、寒毡土 (或寒黑土和草甸土)、暗棕土、棕壤和褐土, 呈明显 的垂直分布 (冯自诚, 1993)。该区大地构造属秦岭 褶皱带西端，以强烈侵蚀切割形成的西部高山峡谷 地貌为主, 海拔 $2000 \sim 4900 \mathrm{~m}$, 山地生境十分复杂, 阳、阴坡水热气候差异很大，阴坡湿润，植被以耐荫 的针叶林为主, 阳坡干燥, 低海拔带植被以阳性针叶 林为主, 高海拔带以柏林和高山灌丛为主。岩石是 以千枚岩为主的变质岩, 易风化剥蚀。

\section{2 研究方法}

\subsection{1 样地调查}

在海拔 $2300 \sim 3600 \mathrm{~m}$ 的范围内, 海拔每升高 $200 \mathrm{~m}$, 在不同的森林群落内采用典型取样法设置样 地。样地面积为 $20 \mathrm{~m} \times 20 \mathrm{~m}$, 每个样地内设置 4 个 $10 \mathrm{~m} \times 10 \mathrm{~m}$ 乔木和灌木样方, 8 个 $1 \mathrm{~m} \times 1 \mathrm{~m}$ 的草本 样方。总共设置样地 36 个, 调查样方共计 576 个。 调查内容包括: 乔木样方对乔木进行每木检尺, 记录 高度、枝下高、冠层厚度、胸径、冠幅、林分郁闭度以 及灌木的种类和株数、群落的发育程度, 灌木样方和 草本样方记录高度、盖度、种类、株数、物候期; 生境 因子记录海拔、坡向、坡度、坡位。野外样方调查在 1997 ～ 1998 年进行。

\subsection{2 物种多样性的测度}

物种多样性指数的测定采用 Simpson 指数 $(D)$ 和 Shannon-Wiener 指数 $(H)$, 公式为 $: D=1-P_{i}^{2} ; H=-$ $\sum P_{i} \ln P_{i}$ 。均匀度指数采用 Pielou 指数 $\left(J_{s w}, J_{s i}\right)$, 公 式为 $: J_{s w}=\left(-\sum P_{i} \ln P_{i}\right) / \ln S$ 和 $J_{s i}=\left(-\sum P_{i}^{2}\right) /(1$ $-1 / S)$ 。其中, $P_{i}$ 为种 $i$ 的相对重要值, $P_{i}=N_{i} / N$; $N_{i}$ 为种 $i$ 的绝对重要值, $N$ 为种 $i$ 所在样方的各个 种的重要值之和, $S$ 为种 $i$ 所在样方的物种总数, 即 物种丰富度指数。在本项研究中, 乔木、灌木和草本 各个种的重要值分别计算, 公式为: 乔木的重要值 $=$ (相对密度 + 相对优势度 + 相对盖度) $/ 3$; 灌木和草本 的重要值 $=($ 相对高度 + 相对盖度 $) / 2$ 。 


\section{2 结果与讨论}

\section{1 群落内物种多样性的空间分布}

森林植物群落的空间结构取决于物种的生长型 和相同生长型的物种组成的层片，选择乔木、灌木和 草本 3 种生长型对群落内植物物种多样性的空间分 布格局进行分析。以相对稳定的顶极或亚顶极群落 密枝杜鹃 (Rhododendron fastigiatum) 灌丛、油松 ( Pinus tabulaeformis) 林、草类云杉( Picea asperata) 林、巴 山冷杉 (Abies fargesii) 林和栎类 (Quercus) 阔叶混交 林为对象, 探讨同一群落内不同层次物种多样性的 特征。巴山冷杉林分为杜鹃巴山冷杉林、箭竹巴山 冷杉林、苔藓巴山冷杉林 3 种群落 栎类阔叶混交林 的建群种是辽东栎 (Quercus liaotungensis)。植物群 落的垂直结构主要受地带性气候所确立的水热组合 影响, 但在一个特定的地带性气候区内 植物群落垂 直层次结构受群落所处的海拔、坡向、坡位等物理微 环境、群落的种群组成、发育阶段、生活史对策的影
响。群落内垂直层次结构及其物种多样性的动态是 群落内垂直生态梯度的直接反映。在选定的群落 内, 受微环境和建群种自身发育特性的影响, 各个群 落生长型的多样性变化各具特点。丰富度指数表现 为乔木层最小, 草本层较大, 灌木层最大 (表 1$)$ 。均 匀度指数变化较为复杂, 在草类云杉林、油松林、栎 类落叶阔叶混交林和箭竹巴山冷杉林中表现为灌木 > 草本 > 乔木, 与丰富度指数一致; 在杜鹃巴山冷杉 林中，灌木种类虽多，但在群落内种的分布并不均 匀, 而草本种类在群落内的分布要均匀得多, 因此表 现为草本 > 灌木 > 乔木 ; 在苔鲜巴山冷杉林中表现 为乔木 $>$ 灌木 $>$ 草本, 主要由于乔木层树种单一, 在 群落内分布相当均匀。多样性指数的变化趋势既不 与丰富度指数一致, 也不与均匀度指数一致, 在杜鹃 巴山冷杉林中表现为乔木层 < 灌木层 <草本层外， 其余群落均表现为乔木层 <草本层 $<$ 灌木层。杜鹃 巴山冷杉林分布海拔较高, 乔木种类仅有两种, 郁闭 度为 $30 \%$ 林内透光较好, 灌木种类虽多, 但杜鹃占

表 1 白龙江上游地区森林群落各生长型的多样性、丰富度、均匀度指数

Table 1 Diversity indexes, richness indexes, and evenness indexes of growth form of several forest communities in the upper reaches of Bailongiiang River

\begin{tabular}{|c|c|c|c|c|c|c|c|}
\hline $\begin{array}{c}\text { 群落类型 } \\
\text { Community types }\end{array}$ & $\begin{array}{c}\text { 郁闭度 } \\
\text { Shade density } \\
(\%)\end{array}$ & $\begin{array}{l}\text { 生长型 } \\
\text { Growth form }\end{array}$ & $S$ & $H$ & $D$ & $J_{s w}$ & $J_{s i}$ \\
\hline 密枝杜鹃灌丛 & 65 & - & - & - & - & - & \\
\hline \multirow[t]{2}{*}{ Rhododendron fastigiatum shrub } & & 灌木 Shrub & 15 & 1.2165 & 0.5224 & 0.4492 & 0.5597 \\
\hline & & 草本 Herb & 8 & 1.0280 & 0.4984 & 0.4945 & 0.5696 \\
\hline \multirow{3}{*}{$\begin{array}{l}\text { 辽东栎阔叶混交林 } \\
\text { Quercus liaotungensis broad-leaved } \\
\text { mixed community }\end{array}$} & 65 & 乔木 Tree & 4 & 0.5000 & 0.2905 & 0.3607 & 0.3873 \\
\hline & & 灌木 Shrub & 21 & 2.0631 & 0.8256 & 0.6776 & 0.8669 \\
\hline & & 草本 Herb & 8 & 0.7364 & 0.5359 & 0.3541 & 0.5507 \\
\hline \multirow{3}{*}{$\begin{array}{l}\text { 油松林 } \\
\text { Pinus tabulaeformis community }\end{array}$} & 70 & 乔木 Tree & 5 & 0.8346 & 0.3683 & 0.5186 & 0.4604 \\
\hline & & 灌木 Shrub & 15 & 2.3491 & 0.8774 & 0.8675 & 0.9401 \\
\hline & & 草本 Herb & 6 & 1.0228 & 0.5582 & 0.5708 & 0.6698 \\
\hline \multirow{3}{*}{$\begin{array}{l}\text { 草类云杉林 } \\
\text { Grasses-Picea asperata community }\end{array}$} & 64 & 乔木 Tree & 5 & 0.7845 & 0.3359 & 0.4874 & 0.4199 \\
\hline & & 灌木 Shrub & 11 & 1.8768 & 0.8445 & 0.7827 & 0.9290 \\
\hline & & 草本 Herb & 6 & 1.3447 & 0.4566 & 0.7505 & 0.5479 \\
\hline \multirow{3}{*}{$\begin{array}{l}\text { 苔藓巴山冷杉林 } \\
\text { Moss-Abies fargesii community }\end{array}$} & 55 & 乔木 Tree & 3 & 0.6274 & 0.4428 & 0.5711 & 0.6642 \\
\hline & & 灌木 Shrub & 11 & 1.1625 & 0.5949 & 0.4848 & 0.6546 \\
\hline & & 草本 Herb & 8 & 0.7604 & 0.4666 & 0.3657 & 0.5333 \\
\hline \multirow{3}{*}{$\begin{array}{l}\text { 杜鹃巴山冷杉林 } \\
\text { Rhododendron-Abies fargesii community }\end{array}$} & 30 & 乔木 Tree & 2 & 0.2035 & 0.0981 & 0.2936 & 0.1962 \\
\hline & & 灌木 Shrub & 11 & 0.6682 & 0.3890 & 0.4152 & 0.4865 \\
\hline & & 草本 Herb & 7 & 1.1340 & 0.7164 & 0.7334 & 0.8596 \\
\hline \multirow{3}{*}{$\begin{array}{l}\text { 箭竹巴山冷杉林 } \\
\text { Bamboo-Abies fargesii community }\end{array}$} & 47 & 乔木 Tree & 3 & 0.4627 & 0.3314 & 0.4212 & 0.4971 \\
\hline & & 灌木 Shrub & 6 & 1.1000 & 0.5923 & 0.6139 & 0.7108 \\
\hline & & 草本 Herb & 5 & 0.9649 & 0.4813 & 0.5995 & 0.6016 \\
\hline
\end{tabular}


灌木总数的 $70 \%$ 以上，一定程度上降低了灌木层的 多样性指数, 而草本层发育良好, 种类相当丰富, 既 有喜光草本,也有耐荫草本, 并且分布均匀, 使其多 样性指数在群落内的空间分布上达到最高; 在其余 群落内, 乔木层的郁闭度较大 林下灌木多为耐荫的 冰川茶蔍子 ( Ribes glaciale)、平枝栒子 ( Cotoneaster horizontalis) 、甘肃忍冬 ( Lonicera kansuensis)、陇塞忍 冬 $(L$. tangutica $) 、$ 华西忍冬 $(L$. webbiana $)$ 等，且随 林内光斑分布 较为均匀, 因而多样性指数最大, 而 乔木层的种类要比灌木和草本少得多,其多样性指 数最小, 草本层居中。群落内垂直结构上物种丰富 度指数和均匀度指数的变化出现分异现象, 主要与 群落内某个种群的绝对数量多少及其在群落内的分 布有关，在一个特定群落内的某一生长型，丰富度指 数与物种总数成正比, 与总个体数成反比, 与个体数 在群落内的分布无关, 而均匀度指数强调个体在群 落内的分布, 即群落内个体数分布越均匀, 均匀度指 数越高。在某一层次内, 当物种丰富度和均匀度指 数都高时, 多样性指数也高; 当丰富度指数低且种群 分布不均匀时, 多样性指数就低。因此,一个具有较 低物种丰富度指数和较高均匀度指数的群落,其多 样性指数可能和一个物种丰富度指数大而均匀度指 数低的群落相同。同时, 草本层和灌木层的物种多 样性受林分郁闭度影响, 呈单峰变化趋势, 且峰值出 现在郁闭度 $50 \%$ 左右。在林分郁闭度为 $30 \%$ 的杜 鹃巴山冷杉林中，灌木层的多样性指数和丰富度指 数明显小于草本层 ; 在郁闭度 $47 \%$ 的箭竹巴山冷杉 林中, 灌木层和草本层的丰富度指数只差 1 ,多样性 指数也比较接近; 在郁闭度 $55 \%$ 以上的各个群落 内 灌木层的多样性指数和丰富度指数均大于草本 层。在本区森林群落中，尽管生物量和所占有的空 间均是乔木层最大, 灌木层次之, 草本层最小, 但其 物种多样性则表现不同趋势, 这与南亚热带森林植 物群落物种多样性的特点类似(黄忠良等 2000)。

植物生长型是表征群落外貌特征和垂直结构的 重要指标(马克平等, 1995)，不同生长型的多样性可 反映出群落在组成、结构、功能和动态方面的立体分 异性。群落内物种多样性空间分布主要受林分垂直 结构的特征和计算物种多样性指数的内涵影响。群 落结构复杂、层次分化多的群落, 物种多样性指数就 高(陈北光等,1995)。在亚热带未受干扰的郁闭常 绿阔叶林分内, 灌木层的物种多样性指数和丰富度 指数较大, 草本层较小, 乔木层居中, 而均匀度指数 在灌木层最低,乔木层最高(李振基等,2000)。因
此 林分郁闭度的变化改变林隙的大小，林隙的大小 又影响各个生长型的物种多样性指数(蔵润国等, 2000)。林隙对物种多样性的影响, 主要通过改变林 分内光照的分布，进而改变各种植物种类对光资源 的利用潜力, 这对草本层和灌木层物种的存在和生 长尤为重要。林分郁闭度较小, 林窗作用较强, 林内 光照充足 给部分喜光灌木和草本的生长提供了机 会 增加了群落内的物种数目; 林分郁闭度越大, 郁 闭作用越强，林分内获取光照资源的机会越少，只有 耐荫的灌木和草本适宜生长 植物种类减少, 多样性 降低。

\section{2 不同坡向森林群落物种多样性特征的比较}

在坡向的影响下,同一海拔范围分布着不同的 林分。选择分布在海拔 2500 2900 m 的草类云杉 林和油松林, 分析坡向对群落多样性特征的影响。 不同生长型的植物对群落结构、功能和生产力的作 用是不同的，因此在计算群落总体多样性时，不能简 单地将各个生长型的指数相加。群落各生长型能进 行光合作用的器官一一叶面积的大小是衡量该生长 型生产力高低的一个重要标志，因此，不同生长型的 叶层(林冠)的相对厚度和相对盖度之和, 可作为测 度群落物种总体多样性时不同生长型的多样性指数 进行加权的参数, 加权参数的计算公式为: $W_{i}=$ $\left(C_{i} / C+H_{i} / H\right) / 2$, 其中 $W_{i}$ 为群落第 $i$ 个生长型多 样性指数的加权参数, $C_{i}$ 为第 $i$ 个生长型的盖度, $H_{i}$ 为第 $i$ 个生长型的平均厚度, $C$ 为群落的总盖 度, $H$ 为群落各生长型平均厚度之和(高贤明等, 1997)。对群落不同生长型的加权参数进行计算后, 再计算各个群落总体物种多样性指数和均匀度指 数。

丰富度指数、均匀度指数、多样性指数在两个群 落间的变化趋势基本一致,均表现为油松林略高于 草类云杉林 (图 1), 这反映了两种群落在组织化水 平间的差异 (黄忠良等,2000)。在海拔变幅不大的 情况下, 坡向促使热量在微环境内重新分配, 成为限 制植物生长的主要因素。阳坡比阴坡温度高, 光照 时数长, 水热组合好(冯自诚, 1993)。草类云杉林生 长在山体的阴坡和半阴坡, 而油松林生长在阳坡。 油松林群落的生境比草类云杉林的生境相对优越， 因而其物种丰富度 $(S=26)$ 比云杉林 $(S=20)$ 大。 油松林乔木层除油松外, 混有少量的青扞 (Picea wilsonii)、青海云杉 ( P. crassifolia)、白华 (Betula platyphylla) 和辽东栋, 灌木种类较多，约 15 种,主要 有尖叶绣线菊 (Spiraea japonica)、陇塞忍冬、鼠李 
( Rhammus davurica)、矮卫矛 (Euonymus nanus)、甘青 锦鸡儿 ( Caragana tangutica) 、西北栒子 (Cotoneaster zabelii)、刺茶蔍子 ( Ribes alpestre)、甘肃荚 $\square$ ( Viburnum kansuense)、鲜黄小檗( Berberis diaphana) 等 草本 主要有野菊 (Dendranthema indicum)、异叶败酱 ( Patrinia heterophylla)、纤毛鹅观草 ( Roegneria ciliaris)、狼 尾花 ( Lysimachia barystachys)、风毛菊（Saussurea japonica) 等, 共 6 种。林内光照分布均匀, 种群在群 落内的分布比较均匀, 均匀度指数高, 多样性指数也 最大。而在草类云杉林内, 乔木主要是云杉, 混生有 青扞、青海云杉，零星分布有巴山冷杉，灌木种类约 11 种, 主要是刚毛忍冬 (Lonicera hispida)、陕甘花楸 (Sorbus koehneana)、鲜黄小檗、钝叶蓄薇 (Rosa serta$t a$ )、中华柳 (Salix cathayana)、短叶锦鸡儿( Caragana brevifolia)、卫矛 (Euonymus sp.) 等,草本有苔草 (Carex hancockiana)、珠芽蓼 (Polygonum viviparum)、 茜草 (Rubia cordifolia) 、旋复花 (Inula japonica)、草莓 (Fragaria gracilis) 等 6 种。多样性指数由丰富度(绝 对密度)和均一性 (相对密度)组成(岳天祥,2001), 也就是说, 多样性指数是把物种数与均匀度结合起 来的一个单一的统计量(钱迎倩等, 1994) ,当一种种 群的数量在群落中占绝对优势时, 组成群落的各个 种群的个体分布就出现明显的不均均匀度降低, 从 而导致群落总体物种多样性指数的下降。两种群落 的乔木层和草本层丰富度指数一样, 而油松林灌木 层的丰富度指数比云杉林的要大, 而且种群分布相 对均匀 增加了其多样性。

\section{3 不同海拔群落多样性特征的比较}

在特定区域内, 群落物种多样性沿海拔梯度的 变化极为显著(马克平等, 1995 )。海拔变化是植物 群落物种分布和组成的决定性因素。植被垂直带谱 为栎类阔叶混交林 (海拔 2 $200 \sim 2500 \mathrm{~m}$ ) 、云杉林 (海拔 $2500 \sim 2800 \mathrm{~m}$ )、巴山冷杉林 (海拔 $2700 \sim$ $3400 \mathrm{~m}$ )、杜鹃灌丛 (海拔 $3300 \sim 3600$ m) (冯自诚, 1993)。栎类阔叶混交林分布在山坡基部, 除建群种 辽东栎外,混生有山杨 (Populus davidiana)、华椴 ( Tilia chinensis)、五角枫 ( Acer mono) ，林下灌木种类 较多, 仅出现在调查样地中的就有 24 种。云杉林分 布在中部。巴山冷杉林的分布范围较大, 下限与云 杉林叠生, 上限是本区森林分布的上限, 随海拔上 升, 依次出现箭竹巴山冷杉林、苔藓巴山冷杉林、杜 鹃巴山冷杉林 3 种不同林型, 杜鹃冷杉林与杜鹃灌 丛相接。

从海拔 $2400 \mathrm{~m}$ 的栎类阔叶混交林 $2600 \mathrm{~m}$ 的

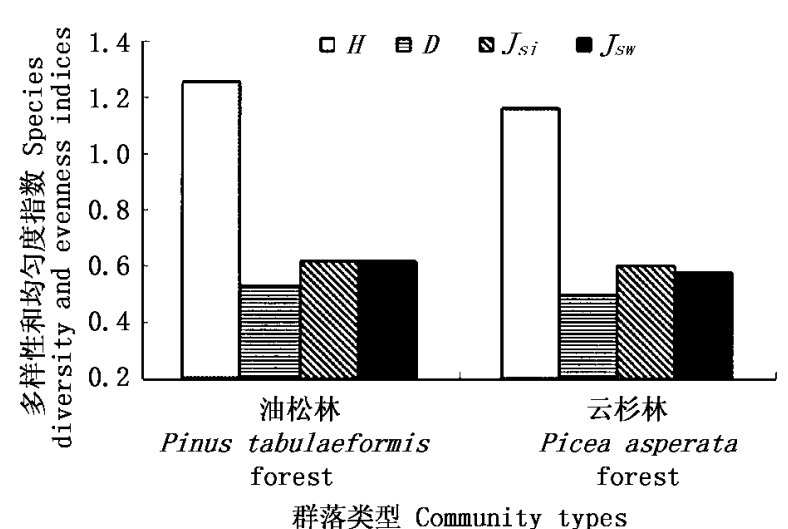

图 1 阳坡油松林和阴坡草类云杉林的植物物种 多样性指数和均匀度指数

Fig. 1 Species diversity and evenness indices of Pinus tabulaeformis community growing on the sunny slope and Picea asperata community growing on the shade slope at the $2500-2700 \mathrm{~m}$ elevation

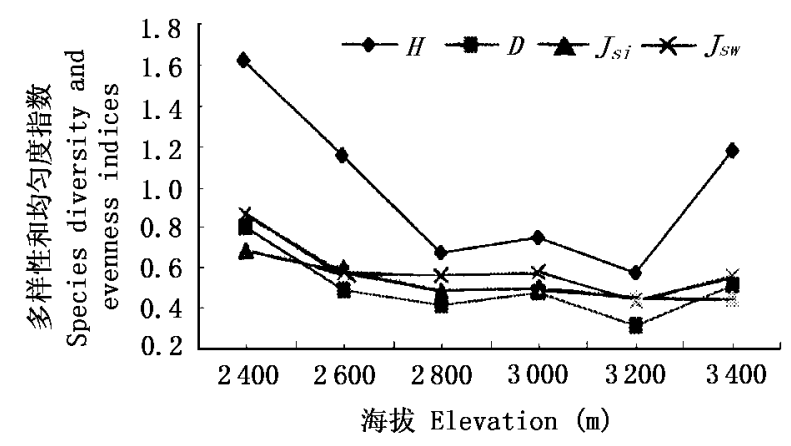

图 2 不同海拔梯度群落的物种多样性指数和均匀度指数

Fig.2 Species diversity and evenness indices of plant communities distributed at different elevations

草类云杉林, $2800 \mathrm{~m}$ 的箭竹巴山冷杉林, $3000 \mathrm{~m}$ 的 苔藓巴山冷杉林 到 $3200 \mathrm{~m}$ 的杜鹃巴山冷杉林, 丰 富度指数、均匀度指数、多样性指数的变化呈单调下 降 到 $3400 \mathrm{~m}$ 的高山密枝杜鹃灌丛时, 物种多样性 增加(图 2)。这与贡嘎山东坡物种多样性在海拔 $1800 \sim 3900 \mathrm{~m}$ 范围内的变化趋势类似(沈泽昊等, 2001)。海拔 $2300 \mathrm{~m}$ 带, 温度较高, 水热组合在本区 内最好, 分布的是栎类阔叶混交林, 虽然乔木种类不 多, 但灌木成分极为复杂, 从地理成分特征分析, 灌 木种类以温带成分为主, 兼有热带成分, 区系起源新 老兼备, 是东西、南北植物的关节点(孙学刚, 1993)。 这种特殊微环境所派生的生境, 促使本区内物种多 样性的最高点出现在海拔最低的地带。随着海拔升 高, 温度逐渐降低, 生物的生境也变得更严酷, 植物 地理成分基本为温带成分, 没有热带成分分布, 生物 多样性逐渐降低, 在海拔 $3200 \mathrm{~m}$ 的杜鹃巴山冷杉 林中, 多样性降至最低。但到海拔 $3400 \mathrm{~m}$ 高山杜 
鹃灌丛带, 群落的物种多样性又升高, 这与人类的经 营活动有关。本区主要是以云杉林和冷杉林为主体 的暗针叶林区，在过去近半个世纪的经营和利用中， 经营方向是用材林, 人类对云杉林和巴山冷杉林的 干扰最为强烈，而对阔叶林和高山杜鹃人为干扰较 少, 同时, 在杜鹃灌丛中, 灌木种类有 15 种, 建群种 为密枝杜鹃,主要伴生种有黄毛杜鹃( Rhododendron rufum)、百里香杜鹃 ( $R$. anthopogonoides )、青海杜鹃 ( R. przewalskii) ,在杜鹃灌丛中零星分布有刚毛忍 冬、鬼箭锦鸡儿 ( Caragana jubata)、山柳 ( Salix pseudotangii)、金露梅 (Potentilla fruticosa) 、高山绣线菊 (Spiraea alpina)、窄叶鲜卑花 (Sibiraea angustata)、杯 腺柳(Salix cupularis)，它们在群落内的分布比较均 匀,因此, 物种多样性较高。在箭竹冷杉林、苔藓冷 杉林和杜鹃冷杉林中, 虽然箭竹冷杉林的分布海拔 较苔藓冷杉林低,但其物种多样性指数却低, 这与箭 竹冷杉林林下灌木箭竹密集、草本和其它灌木入侵 相对较难有关, 而在苔藓巴山冷杉林中, 苔藓层隔离 种子发芽的情况在人为的经营活动中得到改善, 适 宜发芽的灌木和草本种子发芽、生长, 丰富了群落内 的物种种类，且由于没有箭竹和杜鹃的丛生，分布相 对均匀, 因而多样性较高。在杜鹃巴山冷杉林中, 作 为森林分布上限 林下杜鹃所占比重较大, 降低了物 种多样性。
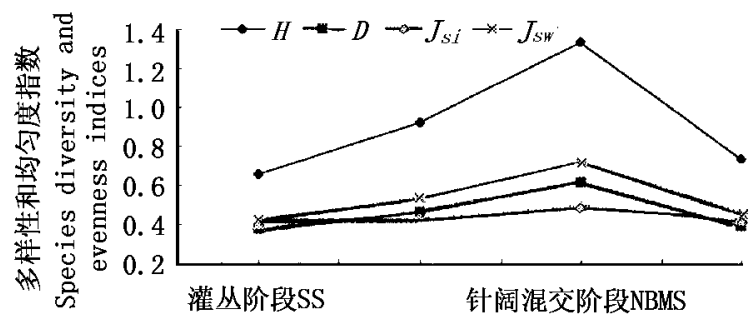

桦类阔叶阶段BBS 针叶林阶段NS

演替阶段 Succession stage

图 3 紫果云杉林演替系列中的物种多样性和均匀度指数

Fig. 3 Species diversity indexes and evenness indices of Picea purpurea community in its succession series

SS 灌丛阶段 Shrubs stage dominated by Spiraea alpina and Sibiraea angustata BBS 桦木阔叶阶段 Broadleaf mixed forest stage dominated by Betula albo-sinensis NBMS : 针阔混交林阶段 Broadleaf and coniferous mixed forest stage dominated by $B$. albo-sinensis and Picea purpurea NS: 针叶林阶段 Coniferous stage forest dominated by $P$. purpurea

\section{4 不同演替阶段物种多样性特征的比较}

森林植物群落是在人为干扰下进行生长发育 的，而分布于该林区的森林植物群落所受的人为干
扰主要是皆伐 (尹作栋等,1991)。以紫果云杉 (Picea purpurea) 林为例, 说明本区主要森林植物群 落在人工干扰条件下演替过程中物种多样性的变化 特点。紫果云杉林被皆伐以后，如果迹地不遭到进 一步破坏，那么将开始由砍伐迹地向顶极或亚顶极 群落演替的漫长过程。由于在不同的年代对紫果云 杉林均有采伐，目前残留的不同采伐期的更新迹地 很多，因而客观上构成了不同演替阶段的群落类型。 紫果云杉林的演替过程大致需要 4 个阶段 ${ }^{1)}$ :1) 灌 丛阶段, 乔木被皆伐后, 形成以高山绣线菊、窄叶鲜 卑花为建群种的落叶灌丛。2) 桦木次生林阶段, 没 有了乔木层的遮荫 林内光照增加，山杨、白桦、红桦 (Betula albo-sinensis)、糙皮桦( B. utilis) 等阔叶阳性 树种迅速入侵, 并形成林冠层, 灌木除高山绣线菊、 窄叶鲜卑花外, 峨嵋蓄薇 (Rosa sertata) 、䊁叶五加 (Acanthopanax henryi)、杯腺柳、山柳等开始迅速发 育 草本层除了原有的耐荫种类外, 也出现了二裂萎 陵菜 (Potentilla bifurca)、冰草 (Agropyron mongolicum) 等喜光种类 植物种类较为丰富。3)紫果云杉桦木 混交林阶段, 由于阔叶树种的遮荫, 紫果云杉幼苗入 侵, 逐渐形成针阔混交林, 这一阶段植物种类最多， 群落已明显分层, 乔木层主要是云杉、青扦等针叶树 种和山杨、桦木等阔叶树种, 灌木增加了陕甘花楸、 北方茶蔍子 ( Ribus maximowizzianum) 、针刺悬钩子 (Rubus pungens)、陇塞忍冬等, 草本层出现大量的禾 叶嵩草 (Kobresia graminifolia)、发草 (Deschampsia caespitosa)、珠芽蓼、皱叶鹿蹄草( Pyrola rugosa) 等。4) 紫果云杉林阶段, 随着紫果云杉的生长, 逐渐占据乔 木层, 阳性阔叶树种逐渐消失, 林下灌木和草本生长 受到抑制 种类减少。

在紫果云杉林的 4 个演替系列中，从采伐迹地 到顶极群落, 丰富度指数呈单峰曲线, 从灌丛阶段、 桦木阔叶林阶段, 到针阔混交林阶段, 各个多样性指 数依次增加, 并在针阔混交林中达到峰值, 当恢复到 紫果云杉林阶段时, 各个指数又下降, 但不是最低 (图 3)。在紫果云杉桦木混交林阶段 (1958 年皆伐 迹地天然恢复的群落) ,没有明显的建群种, 针叶树 种除紫果云杉占有很大比重外，还有少量的云杉、青 扞, 阔叶树种主要是白榫和红桦, 也有山杨分布, 林 内灌木层和草本层发育良好, 灌木主要有钝叶菩薇、 陇塞忍冬、刚毛忍冬、陕甘花楸、鲜黄小檗、短叶锦鸡 儿、矮卫矛、珍珠梅、披针苔草 (Carexlanceolata)、珠 
芽蓼、旋复花、茜草、车前 (Plantago asiatica) 等, 植物 种类较多, 丰富度指数最大。均匀度指数的变化趋 势与丰富度指数类似，但没有其剧烈，相对平稳。因 此多样性指数的变化趋势与丰富度指数和均匀度指 数类似。

\section{3 小 结}

森林植物群落内生长型的物种多样性空间分布 特征主要受某一种群数量在群落内的分布状况和植 物种类多少的影响, 同时, 乔木层的郁闭度也是影响 群落内各层间物种多样性变化的主要因素。几种稳 定群落生长型的丰富度指数大小的顺序为 :灌木层 $>$ 草本层 $>$ 乔木层。均匀度指数变化比较复杂, 在 杜鹃巴山冷杉林中为草本 > 灌木 > 乔木, 苔鲜巴山 冷杉林中乔木 $>$ 灌木 $>$ 草本, 其余群落内与丰富度 指数类似。多样性表现为乔木层最低, 灌木层和草 本层的多样性受乔木层郁闭度影响, 在林分郁闭度 $30 \%$ 的杜鹃巴山冷杉林中, 草本层的多样性大于灌 木层, 在林分郁闭度 $47 \%$ 的箭竹巴山冷杉林中, 草 本层多样性和灌木层多样性几乎相当, 在郁闭度大 于 55\%的草类云杉林、油松林、箭竹云杉林、杜鹃灌 丛、苔藓巴山冷杉林中, 灌木层的多样性大于草本 层。在同一海拔带内, 坡向对群落物种多样性的影 响十分显著。在海拔 $2700 \sim 2900 \mathrm{~m}$ 的范围内, 分 布于阳坡的油松林物种多样性大于分布于阴坡的草 类云杉林, 主要是阳坡的水热组合比阴坡好。物种 多样性沿海拔的上升表现为先下降后上升的变化趋 势, 在海拔 $2400 \sim 3200 \mathrm{~m}$ 的范围内, 多样性呈下降 趋势 到 $3200 \mathrm{~m}$ 的杜鹃巴山冷杉林时最低, 但分布 在海拔 $3400 \mathrm{~m}$ 处的高山杜鹃灌丛, 其多样性要高 于杜鹃巴山冷杉林, 这与人类对森林群落的经营活 动相关。在草类云杉林的演替系列中, 物种多样性 先上升,后下降,在针阔混交林阶段最高。

\section{参 考 文 献}

Bai, Y. F., L. H. Li, J. H. Huang \& Z. Z. Chen. 2001. The influence of plant diversity and functional composition on ecosystem stability of four Stipa communities in the Inner Mongolia plateau. Acta Botanica Sinica(植物学报), $43: 280 \sim 287$.

Chang, X. L. (常学礼) \& J. G. Wu (乌建国). 1997. Species diversity during desertification on Kerqin Sandy Land. Chinese Journal of Applied Ecology (应用生态学报), 8: 151 156 . (in Chinese with English abstract)

Chang, X. L. (常学礼) , A. F. Zhao(赵爱芬) \& S. G. Li(李 胜功 ). 2000. Responses of species diversity to precipitation change on fixed-dunes of the Naiman Banner region. Acta Phytoecologica Sinica (植物生态学报), 24: 147 151. (in Chinese with English abstract)
Chen, B. G. (陈北光) \& Z. Y. Su (苏志尧) . 1995. Species diversity of evergreen broadleaved forest in Babaosha Nature Reserve, Guangdong. Journal of South China Agricultural University (华南农业大学学报), 16(4) : 32 36. (in Chinese with English abstract)

Feng, Z. C. (冯自诚). 1993. Relativity analysis of forest growth and site conditions in the mid-upper reaches of Bailong River. Journal of Gansu Agricultural University (甘肃农业大学学报), 28 (Supp.) :2 20. (in Chinese with English abstract)

Gao, X. M. (高贤明), J. H. Huang (黄建辉), S. Q. Wan (万师强) \& L. Z. Chen (陈灵芝) . 1997. Ecological study on the plant community succession on the abandoned cropland in Taibaishan, Qinling Mountains. I. The community $\alpha$ diversity feature of the successional series. Acta Ecologica Sinica (生态学 报), 17:619 625. (in Chinese with English abstract)

Guo, Z. G. (郭正刚) \& B. L. Wu(吴秉礼) . 1999. Application of gray theory in prediction of stand volume. Journal of Gansu Agricultural University (甘肃农业大学学报), 34(2) : 171 174 . (in Chinese with English abstract)

Huang, Z. L. (黄忠良), G. H. Kong (孔国辉) \& D. Q. He (何道泉).2000. Plant community diversity in Dinghushan Nature Reserve. Acta Ecologica Sinica (生态学报), 20:193 198. (in Chinese with English abstract)

Li, Y. H. (李永宏). 1995. Sustainable management principles of grassland ecosystem. In: Li, B. (李博) ed. Lectures on modern ecology. Beijing: Science Press. 79 88. (in Chinese)

Li, X. R. (李新荣), J. G. Zhang(张景光), L. C. Liu(刘立 超), H. S. Chen (陈怀顺) \& Q. H. Shi (石庆辉). 2000. Plant diversity in the process of succession of artificial vegetation types and environment in an arid desert region of China. Acta Phytoecologica Sinica (植物生态学报), 24:257 261. (in Chinese with English abstract)

Li, Z. J. (李振基), C. D. Liu (刘初钿), Z. W. Yang (杨志 伟), J. Y. He (何建源) \& P. Lin (林鹏). 2000. Study on the species diversity of the closed stable forest and the disturbed forest of Castanopsis eyrei in Wuyishan National Nature Reserve. Acta Phytoecologica Sinica (植物生态学报), 24:64 68. (in Chinese with English abstract)

Liu, H. M. (刘宏茂) , Z. F. Xu (许再富) \& A. G. Chen (陈 爱国) . 1998. An assessment of impacts of land use on plant biodiversity in Xishuangbanna, southwest China. Acta Phytoecologica Sinica (植物生态学报), 22:257 261. (in Chinese with English abstract)

Ma, K. P. (马克平), J. H. Huang (黄建辉), S. L. Yu (于顺 利) \& L. Z. Chen (陈灵芝) . 1995. Plant community diversity in Dongling Mountain, Beijing, China. II . Species richness, evenness and species diversities. Acta Ecologica Sinica (生态学 报), 15:268 277. (in Chinese with English abstract)

Qian, Y. Q. (钱迎倩) \& K. P. Ma(马克平).1994. Principles and methodologies of biodiversity studies. Beijing: Chinese Science and Technology Press. (in Chinese)

Qu，Y. N. (曲永宁) \& X. Bai (白星). 1996. Study on regeneration of the Picea and Abies forest in the upper reaches of Bailong River. Journal of Gansu Forestry Science and Technology (甘肃林业科技)，21(4) : 45 48. (in Chinese with English abstract)

Shen, Z. H. (沈泽昊)，J. Y. Fang (方精云)，Z. L. Liu (刘 增力）\& J. Wu (伍杰). 2001. Patterns of biodiversity along the vertical vegetation spectrum of the east aspect of Gongga Mountain. Acta Phytoecologica Sinica (植物生态学报), 25: $721 \sim 732$. (in Chinese with English abstract) 
Sun, X. G. (孙学刚). 1993. Study on the forest flora in the midupper reaches of the Bailong River. Journal of Gansu Agricultural University (甘肃农业大学学报), 28 (Supp.) : 65 78. (in Chinese with English abstract)

Wen, Y. G. (温远光), C. A. Yuan(元昌安), X. X. Li(李信 贤), T. P. He (和太平), J. Y. Lai (赖家业) \& M. Huang (黄棉). 1998. Development of species diversity in vegetation restoration process in mid-mountain region of Damingshan, Guangxi. Acta Phytoecologica Sinica (植物生态学报), 22:33 $\sim 40$. (in Chinese with English abstract)

Yang, L. M. (杨利民), M. Han(韩梅) \& J. D. Li(李建东). 2001. Plant diversity change in grassland communities along a grazing disturbance in the northeast China transect. Acta Phytoecologica Sinica (植物生态学报), 25:110 114. (in Chinese with English abstract)

Yin, Z. D. (尹作栋) \& Z. F. Hao (赫卓峰). 1991. The comprehensive papers of investigation in the Bailong River and Taohe stand region. Shanghai: Shanghai Science and Technology Press. (in Chinese)
Yue, T. X. (岳天祥).2001. Studies and questions of biological diversity. Acta Ecologica Sinica(生态学报), 21:462 467. (in Chinese with English abstract)

Zang, R. G. (藏润国), B. S. Wang (王伯荪) \& J. Y. Liu (刘 静艳) . 2000. Tree species diversity in gaps of different sizes and development stages in lower subtropical evergreen broadleaved forest, south China. Chinese Journal of Applied Ecology (应用 生态学报), 11:485 488. (in Chinese with English abstract)

Zang, R. G. (藏润国) \& T. Liu(刘涛). 1997. Type classification, tree species diversity and niche analysis for the post cutting Korean pine-broadleaved forest in the Baishishan forest of Jilin province. Journal of Beijing Forestry University (北京林业大学 学报), 19(1):51 56. (in Chinese with English abstract)

Zhu, J. M. (朱锦惁), Z. L. Jiang (姜志林) \& Q. R. Zheng (郑群瑞). 1995. Study on the species diversity of the forest communities in the Wanmulin Nature Reserve of Fujian. Journal of Nanjing Forestry University (南京林业大学学报), 21 (4): $11 \sim 16$. ( in Chinese with English abstract)

责任编委 : 陈灵芝 责任编辑 :周玉荣 